\title{
Efficient bioconversion of 2,3-butanediol into acetoin using Gluconobacter oxydans DSM 2003
}

\author{
Xiuqing Wang ${ }^{1}$, Min Lv ${ }^{1}$, Lijie Zhang ${ }^{1}$, Kun Li ${ }^{1}$, Chao Gao ${ }^{1 *}$, Cuiqing Ma ${ }^{1}$ and Ping Xu
}

\begin{abstract}
Background: 2,3-Butanediol is a platform and fuel biochemical that can be efficiently produced from biomass. However, a value-added process for this chemical has not yet been developed. To expand the utilization of 2,3-butanediol produced from biomass, an improved derivative process of 2,3-butanediol is desirable.

Results: In this study, a Gluconobacter oxydans strain DSM 2003 was found to have the ability to transform 2,3-butanediol into acetoin, a high value feedstock that can be widely used in dairy and cosmetic products, and chemical synthesis. All three stereoisomers, meso-2,3-butanediol, (2R,3R)-2,3-butanediol, and (2S,3S)-2,3-butanediol, could be transformed into acetoin by the strain. After optimization of the bioconversion conditions, the optimum growth temperature for acetoin production by strain DSM 2003 was found to be $30^{\circ} \mathrm{C}$ and the medium $\mathrm{pH}$ was 6.0. With an initial 2,3-butanediol concentration of $40 \mathrm{~g} / \mathrm{L}$, acetoin at a high concentration of $89.2 \mathrm{~g} / \mathrm{L}$ was obtained from 2,3-butanediol by fed-batch bioconversion with a high productivity $(1.24 \mathrm{~g} / \mathrm{L} \cdot \mathrm{h})$ and high yield (0.912 $\mathrm{mol} / \mathrm{mol})$.

Conclusions: G. oxydans DSM 2003 is the first strain that can be used in the direct production of acetoin from 2,3-butanediol. The product concentration and yield of the novel process are both new records for acetoin production. The results demonstrate that the method developed in this study could provide a promising process for efficient acetoin production and industrially produced 2,3-butanediol utilization.
\end{abstract}

Keywords: 2,3-butanediol, Acetoin, Gluconobacter oxydans, Bioconversion

\section{Background}

2,3-Butanediol is a platform and fuel biochemical $(<\mathrm{US}$ $\$ 1 / \mathrm{kg}$ ) that can be produced by biotechnological routes. With a high heating value of $27,200 \mathrm{~J} / \mathrm{g}$, it can be used as a liquid fuel or fuel additive [1-3]. Many microorganisms including Bacillus, Klebsiella, Enterobacter, Saccharomyces, and Serratia have been used to efficiently produce 2,3-butanediol [4-10]. Although some efficient and economical 2,3-butanediol fermentation processes have been established in laboratory studies [11-15], it has not been produced in a large scale. The reason is because a sizable derivative process for this chemical has not yet been developed until now. Hence, the development of improved derivative processes of 2,3-butanediol would be a prerequisite for commercial utilization of industrially produced 2,3-butanediol.

\footnotetext{
* Correspondence: jieerbu@sdu.edu.cn

${ }^{1}$ State Key Laboratory of Microbial Technology, Shandong University, Jinan 250100, People's Republic of China

Full list of author information is available at the end of the article
}

Several interesting chemical reactions, such as dehydration, dehydrogenation, ketalization, and esterification, could be used for the preparation of 2,3-butanediol derivatives (Figure 1). Among those derivative processes of 2,3butanediol, only dehydrogenation of 2,3-butanediol to produce acetoin could be performed by biotechnological routes. Acetoin is a high value product that can be widely used not only in dairy products, but also in cosmetics, pharmaceutical, and chemical synthesis [16-19]. It is one of the 30 platform chemicals that are given priority to their development and utilization by the US Department of Energy. Thus, numerous studies have been executed to find an effective biocatalytic process to produce acetoin from 2,3-butanediol. For example, Yamada-Onodera et al. reported that $8.4 \mathrm{~g} / \mathrm{L}$ of acetoin was obtained from 2,3butanediol after 24 hours of incubation with recombinant Escherichia coli expressing glycerol dehydrogenase [20]. A recombinant $E$. coli strain that coexpressed $(2 R, 3 R)-2,3-$ butanediol dehydrogenase and NADH oxidase was also constructed, and the highest yield of acetoin was found to 


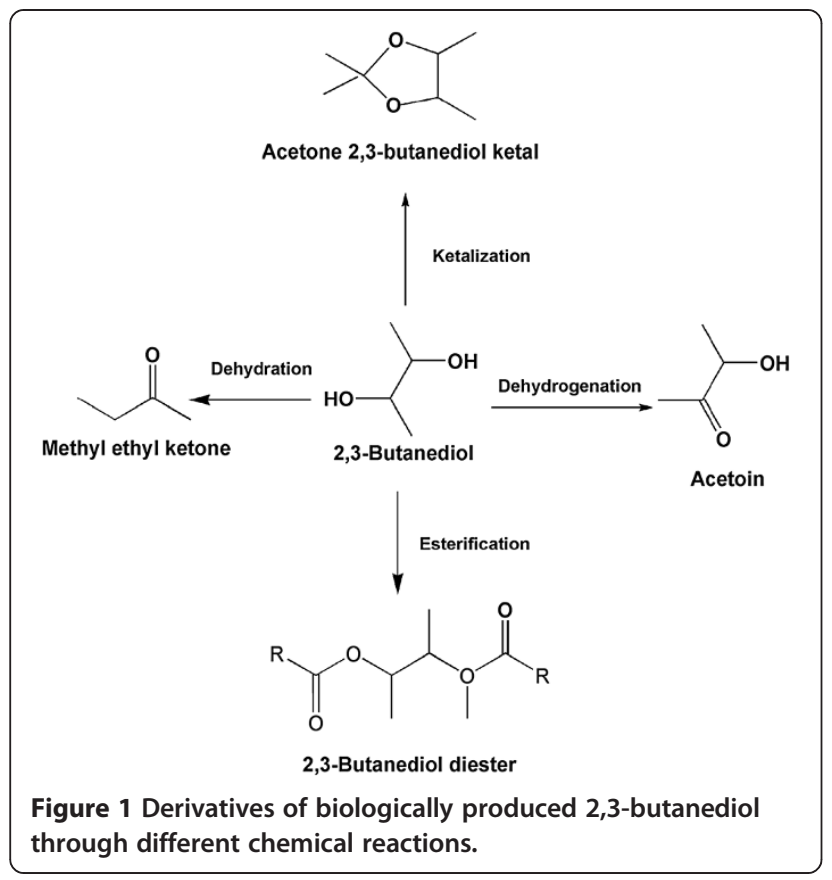

be $36.7 \mathrm{~g} / \mathrm{L}$ [21]. However, in these biocatalytic processes, biocatalysts must be cultivated, separated, and washed before being used in the production of acetoin; such a complicated operation presents a significant drawback for the application of the method.

Production of acetoin using 2,3-butanediol as the sole carbon source does not require the separation of biocatalysts from growth medium. It is an interesting concept, but unfortunately acetoin can be metabolized by numerous microorganisms [22-25]. A microorganism that could directly produce acetoin from 2,3-butanediol through bioconversion has never been reported. Thus, it would be desirable to find an effective microorganism for the direct production of acetoin from 2,3-butanediol.

In this study, Gluconobacter oxydans DSM 2003, an obligate aerobic Gram-negative bacterium, was confirmed to have the ability to produce acetoin from 2,3-butanediol. After optimization of reaction conditions, production of acetoin from 2,3-butanediol using G. oxydans DSM 2003 was acquired. The process presented in this study could provide a promising alternative for the value-added utilization of biotechnologically produced 2,3-butanediol from biomass.

\section{Results and discussion}

\section{G. oxydans DSM 2003 has the capacity for acetoin production from 2,3-butanediol}

G. oxydans has a respiratory metabolism characterized by incomplete oxidation of sugars, alcohols, and acids. The partially oxidized products (aldehyde, ketone, and organic acid) are rapidly excreted into the medium. This property makes G. oxydans an important biocatalyst for industrial use [26-28]. In a previous study, many substrates including glycerol, meso-erythritol, 1,3-butanediol, and 2,3-butanediol could be oxidized by the membrane-bound polyol dehydrogenase (GOX 0854 and GOX 0855) in G. oxydans $621 \mathrm{H}$ [29]. Homologues of GOX 0854 and GOX 0855 were present in other $G$. oxydans strains, such as $G$. oxydans H24, G. oxydans DSM 7145, and G. oxydans IFO 3255 [30-32]. Thus, most strains of G. oxydans, such as G. oxydans DSM 2003, might have the metabolic potential to directly produce acetoin from 2,3-butanediol.

To determine whether the G. oxydans DSM 2003 has the capability to produce acetoin from 2,3-butanediol, the strain was cultured in a medium containing $20 \mathrm{~g}$ yeast extract, $1.5 \mathrm{~g}\left(\mathrm{NH}_{4}\right)_{2} \mathrm{SO}_{4}, 1.5 \mathrm{~g} \mathrm{KH}_{2} \mathrm{PO}_{4}$, and $0.5 \mathrm{~g}$ $\mathrm{MgSO}_{4} 7 \mathrm{H}_{2} \mathrm{O}$ in $1 \mathrm{~L}$ of distilled water. This medium was supplemented with $10 \mathrm{~g} / \mathrm{L}$ 2,3-butanediol. The flask experiment was conducted in $300 \mathrm{~mL}$ shake flasks containing $50 \mathrm{~mL}$ fresh medium for 12 hours at $200 \mathrm{rpm}$ and $30^{\circ} \mathrm{C}$. As shown in Figure 2, $9.6 \mathrm{~g} / \mathrm{L}$ acetoin was obtained in 12 hours. However, little growth of G. oxydans DSM 2003 and no production of acetoin were detected in the medium that contained $20 \mathrm{~g} / \mathrm{L}$ yeast extract (Additional file 1: Figure S1A). G. oxydans DSM 2003 was also cultured in the medium containing $10 \mathrm{~g} / \mathrm{L}$ glycerol, a good carbon source for the growth of the strain. Although a higher growth of the strain was detected, no production of acetoin was detected in the medium containing $10 \mathrm{~g} / \mathrm{L}$ glycerol (Additional file 1: Figure S1B). On the other hand, homologues of key enzymes in 2,3butanediol synthesis pathway ( $\alpha$-acetolactate synthase and $\alpha$-acetolactate decarboxylase) were absent in the genome sequenced G. oxydans strains including G. oxydans $621 \mathrm{H}$, G. oxydans H24, and G. oxydans WSH-003 [32-34]. Thus, there might not be a 2,3-butanediol producing pathway in G. oxydans DSM 2003. Acetoin was

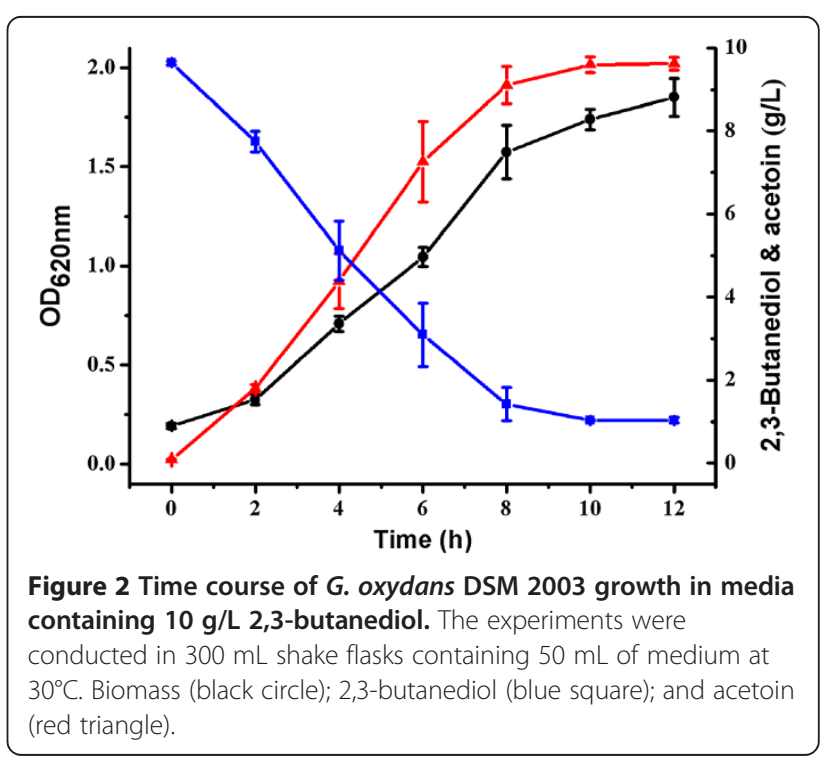


produced by a direct dehydrogenation reaction of 2,3butanediol in the medium.

\section{All three stereoisomers of 2,3-butanediol are utilized by G. oxydans DSM 2003}

2,3-Butanediol has three stereoisomers including meso2,3-butanediol, (2R,3R)-2,3-butanediol, and (2S,3S)-2,3butanediol. Different microorganisms produce different stereoisomers of 2,3-butanediol. For example, strains of Bacillus, such as Bacillus licheniformis, and Paenibacillus polymyxa produce $(2 R, 3 R)-2,3$-butanediol as the major product [7,35]. Serratia marcescens produces meso-2,3butanediol as the major product [11]. Other strains including Klebsiella pneumoniae, Klebsiella oxytoca, and Enterobacter cloacae produce meso-2,3-butanediol and $(2 S, 3 S)-2,3$-butanediol as the major products [4,5,9]. In this study, a commercial 2,3-butanediol, which contained 15.9\% (2R,3R)-2,3-butanediol, 76.1\% meso-2,3-butanediol, and $8.0 \%(2 S, 3 S)-2,3$-butanediol, was used as the carbon source for G. oxydans DSM 2003. After the bioconversion process, the stereoisomeric composition of 2,3-butanediol was analyzed by gas chromatography (GC) with a flame ionization detector and a fused silica capillary column.

All three stereoisomers of 2,3-butanediol including meso-2,3-butanediol, (2R,3R)-2,3-butanediol, and (2S,3S)2,3-butanediol could be utilized by G. oxydans DSM 2003. Both $(3 S)$-acetoin and $(3 R)$-acetoin were the final products of the bioconversion process. Thus, the 2,3-butanediol produced by the reported microorganisms could be used by G. oxydans DSM 2003 for acetoin production.

\section{G. oxydans DSM 2003 catalyzes 2,3-butanediol into acetoin with stereoselectivity}

Among all of the 2,3-butanediol producing strains, 2,3-butanediol was produced by NAD-dependent 2,3butanediol dehydrogenase, catalyzing the stereoselective reduction of acetoin [2]. Several 2,3-butanediol dehydrogenases with different stereospecificities have been previously studied. 2,3-Butanediol dehydrogenase could also catalyze the oxidation of 2,3-butanediol to produce acetoin. For example, $(2 R, 3 R)$-2,3-butanediol dehydrogenase in Bacillus subtilis, Saccharomyces cerevisiae, and Paenibacillus polymyxa can catalyze the stereospecific oxidation of $(2 R, 3 R)$-2,3-butanediol and meso-2,3-butanediol to $(3 R)$-acetoin and (3S)-acetoin, respectively [36-38]. meso2,3-Butanediol dehydrogenase in S. marcescens H30 can catalyze the stereospecific oxidation of $(2 S, 3 S)$-2,3-butanediol and meso-2,3-butanediol to (3S)-acetoin and (3R)acetoin, respectively [39]. To identify the stereoselectivity of 2,3-butanediol dehydrogenase in G. oxydans DSM 2003 that catalyzes the oxidation of 2,3-butanediol, biotransformation with 2,3-butanediol as the substrate and whole cells of G. oxydans DSM 2003 as the catalyst was conducted. After accomplishing the reaction with meso-2,3- butanediol, (2R,3R)-2,3-butanediol, or (2S,3S)-2,3-butanediol as the substrate, the mixture was centrifuged and the concentrations of $(3 S)$-acetoin and $(3 R)$-acetoin in the supernatant were analyzed by $\mathrm{GC}$, respectively.

When $(2 R, 3 R)$-2,3-butanediol was used as the substrate, $(3 R)$-acetoin was the major product detected. Accordingly, (3S)-acetoin was, as expected, the major product obtained from $(2 S, 3 S)$-2,3-butanediol. Furthermore, (3S)-acetoin could be obtained from meso-2,3butanediol. On the other hand, as shown in Additional file 2: Figure S2A and Figure S2B (analyzed by HPLC), $(3 S)$-acetoin and $(3 R)$-acetoin could not be further transformed into diacetyl by G. oxydans DSM 2003, which is similar to the situation in most of the 2,3-butanediol producing strains.

Chiral acetoin is widely used to synthesize novel optically active $\alpha$-hydroxy ketone derivatives and liquid crystal composites. Numerous biocatalytic processes for the production of chiral acetoin have been reported [40,41]. $(2 R, 3 R)-2,3$-Butanediol and meso-2,3-butanediol could be easily produced by $P$. polymyxa and $S$. marcescens, respectively $[7,11]$. Due to the high stereoselectivity in the G. oxydans DSM 2003 catalyzed 2,3-butanediol oxidation, this strain might also provide a promising alternative for the production of (3S)-acetoin and (3R)-acetoin.

\section{G. oxydans DSM 2003 constitutively expresses enzymes in 2,3-butanediol oxidation}

In G. oxydans $621 \mathrm{H}$, the polyol dehydrogenase (GOX 0854 and GOX 0855) exhibited 2,3-butanediol dehydrogenase activity [29]. This enzyme was reported as a membranebound protein and uses ubiquinone as the native electron acceptor. To identify whether G. oxydans DSM 2003 has a similar 2,3-butanediol dehydrogenase activity, a whole-cell 2,6-dichlorophenolindophenol (DCPIP) assay was used [29]. Corresponding to the result of biotransformation experiments, meso-2,3-butanediol, (2R,3R)-2,3-butanediol, and $(2 S, 3 S)$-2,3-butanediol could be oxidized by whole cells of G. oxydans DSM 2003, implying the presence of a 2,3butanediol dehydrogenase activity in the strain.

To assess the expression of 2,3-butanediol dehydrogenase activity, G. oxydans DSM 2003 was cultured with different carbon sources, and the specific activities of 2,3-butanediol dehydrogenases were examined. The specific activities of the enzymes in cells grown on 2,3-butanediol were similar to those of cells grown on glucose, glycerol, and sorbitol (Additional file 3: Table S1). This result is consistent with polyol dehydrogenase in G. oxydans $621 \mathrm{H}$, whose expression was also constitutive [29]. However, to further identify whether the homologues of GOX 0854 and GOX 0855 catalyze the oxidation of 2,3butanediol in G. oxydans DSM 2003, deletion and function analysis of the corresponding genes should be conducted in successive studies. 


\section{Optimal pH for acetoin production}

To increase the efficiency of acetoin production, the bioconversion conditions of G. oxydans DSM 2003 were optimized. The effects of the $\mathrm{pH}$ (5.5 to 7.5) of the culture medium on growth of G. oxydans DSM 2003, 2,3-butanediol utilization, and acetoin production were investigated in $300 \mathrm{~mL}$ shake flasks containing $50 \mathrm{~mL}$ medium with approximately $10 \mathrm{~g} / \mathrm{L}$ 2,3-butanediol.

As shown in Figure 3C, the highest concentration of acetoin was $9.4 \mathrm{~g} / \mathrm{L}$ when the initial $\mathrm{pH}$ of the culture medium was set at 6.0. 2,3-Butanediol $(9.8 \mathrm{~g} / \mathrm{L})$ was nearly completely depleted during 12 hours of bioconversion (Figure 3B). The product yield was at $98.1 \%$ of the theoretical value $(1 \mathrm{~mol} / \mathrm{mol})$. Consequently, the initial $\mathrm{pH}$ of 6.0 was chosen for subsequent bioconversions.

\section{Optimal temperature for acetoin production}

Efficiency of the bioconversion processes is temperaturedependent owing to the strict dependence of enzymatic activity and cellular maintenance upon temperature. In this study, the effects of temperature $\left(16^{\circ} \mathrm{C}, 25^{\circ} \mathrm{C}, 30^{\circ} \mathrm{C}\right.$, and $35^{\circ} \mathrm{C}$ ) on cell growth, acetoin production, and 2,3butanediol utilization were also examined.

As shown in Figure 4A and Figure 4C, the best growth of G. oxydans DSM 2003 and yield of acetoin were obtained when the temperature was maintained at $30^{\circ} \mathrm{C}$. Since the G. oxydans strain could not grow at a temperature higher than $37^{\circ} \mathrm{C}$, a temperature of $30^{\circ} \mathrm{C}$ was chosen for subsequent bioconversions.

\section{Optimal 2,3-butanediol concentration for acetoin production}

To study the effect of the initial 2,3-butanediol concentration on acetoin production, various concentrations of 2,3-butanediol were utilized by G. oxydans DSM 2003 in batch process to produce acetoin. The effects of 2,3butanediol concentration on cell and acetoin production were examined after 24 hours of bioconversion in $300 \mathrm{~mL}$ shake flasks containing $10 \mathrm{~g} / \mathrm{L}, 20 \mathrm{~g} / \mathrm{L}, 40 \mathrm{~g} / \mathrm{L}$, $60 \mathrm{~g} / \mathrm{L}$, and $80 \mathrm{~g} / \mathrm{L}$ 2,3-butanediol, respectively.

As shown in Figure 5A, cell density increased with the 2,3-butanediol concentrations to $40 \mathrm{~g} / \mathrm{L}$, and then decreased. The production of acetoin increased significantly with an increase of 2,3-butanediol concentrations from $10 \mathrm{~g} / \mathrm{L}$ to $40 \mathrm{~g} / \mathrm{L}$ (Figure $5 \mathrm{~B}$ ). When the 2,3-butanediol concentration was over $40 \mathrm{~g} / \mathrm{L}$, both cell density and acetoin concentration decreased sharply. This result showed that the high initial substrate concentration would affect the metabolism of strain G. oxydans DSM 2003. Thus, 2,3-butanediol at a concentration of $40 \mathrm{~g} / \mathrm{L}$ was chosen for subsequent studies.

\section{Batch bioconversion under optimum conditions}

Combining the results mentioned above, an optimal system for the production of acetoin from 2,3-butanediol

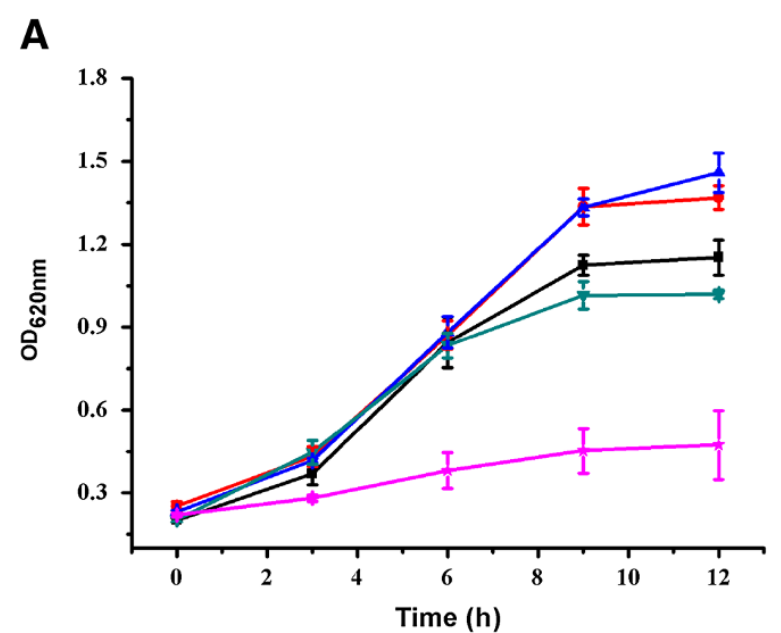

B

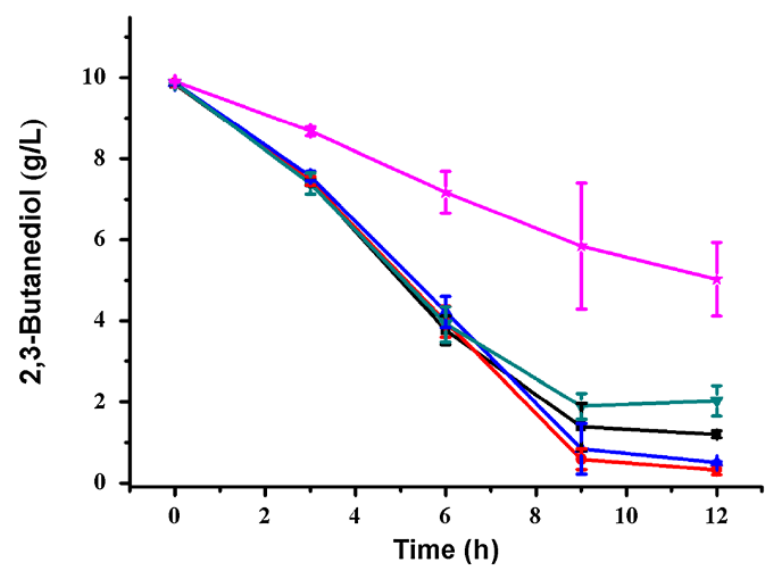

C

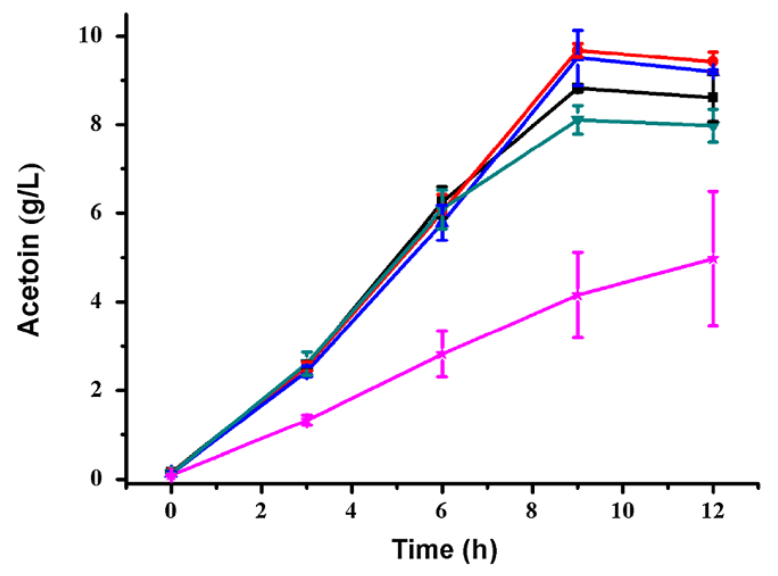

Figure 3 Effect of $\mathrm{pH}$ on acetoin production by $\mathrm{G}$. oxydans DSM 2003. (A) Biomass; (B) 2,3-butanediol; and (C) acetoin. The experiments were conducted in $300 \mathrm{~mL}$ shake flasks containing $50 \mathrm{~mL}$ of medium at $30^{\circ} \mathrm{C}$. The $\mathrm{pH}$ was adjusted at 5.5 (black square), 6.0 (red circle), 6.5 (blue triangle), 7.0 (dark green downpointing triangle), and 7.5 (pink star). 


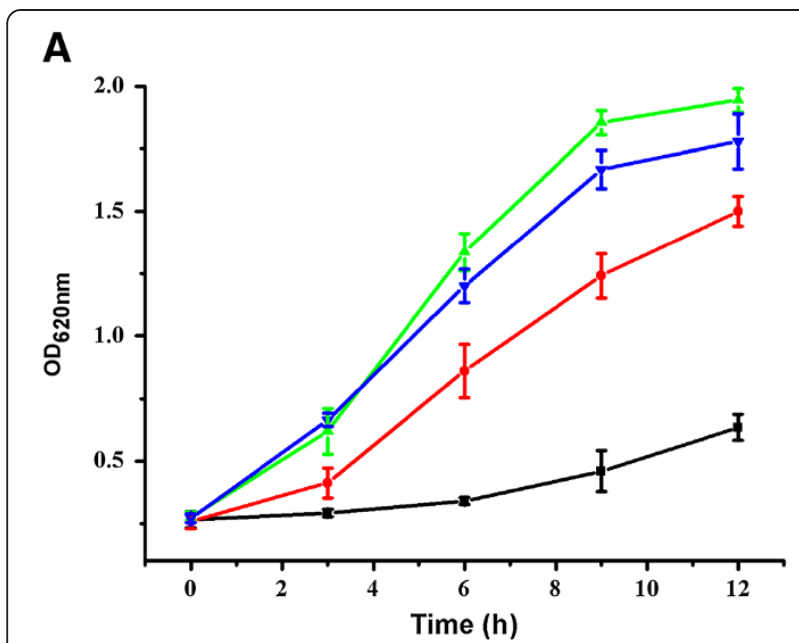

B

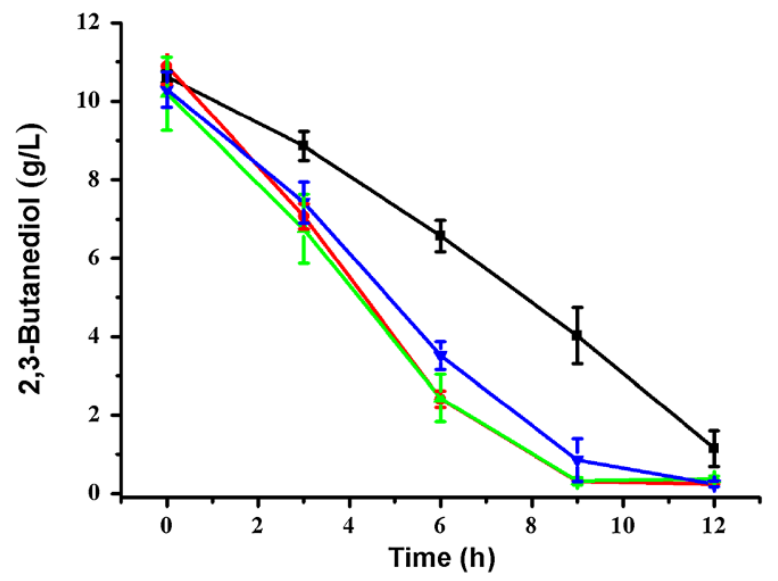

C

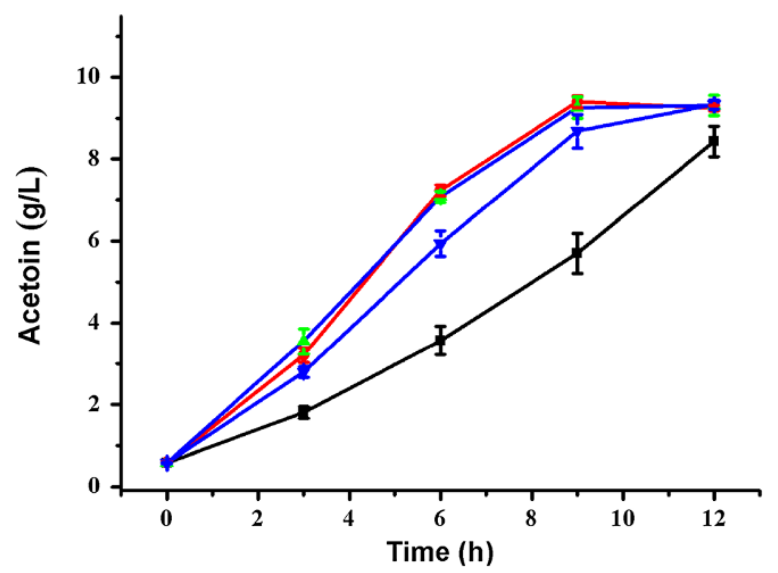

Figure 4 Effect of temperature on acetoin production by G. oxydans DSM 2003. (A) Biomass; (B) 2,3-butanediol; and (C) acetoin. The experiments were conducted in $300 \mathrm{~mL}$ shake flasks containing $50 \mathrm{~mL}$ of medium at $\mathrm{pH}$ 6.0. The temperature was adjusted at $16^{\circ} \mathrm{C}$ (black square), $25^{\circ} \mathrm{C}$ (red circle), $30^{\circ} \mathrm{C}$ (green triangle), and $35^{\circ} \mathrm{C}$ (blue down-pointing triangle).

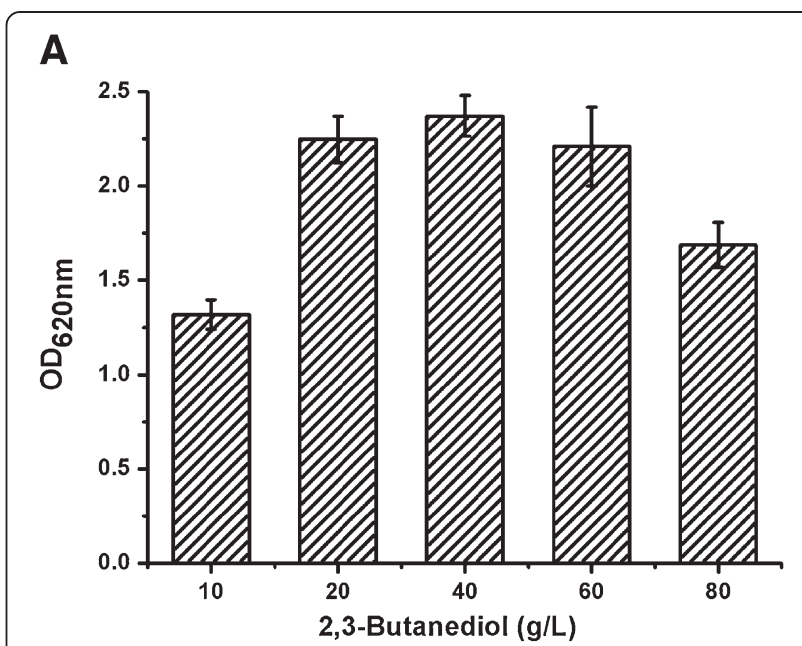

B

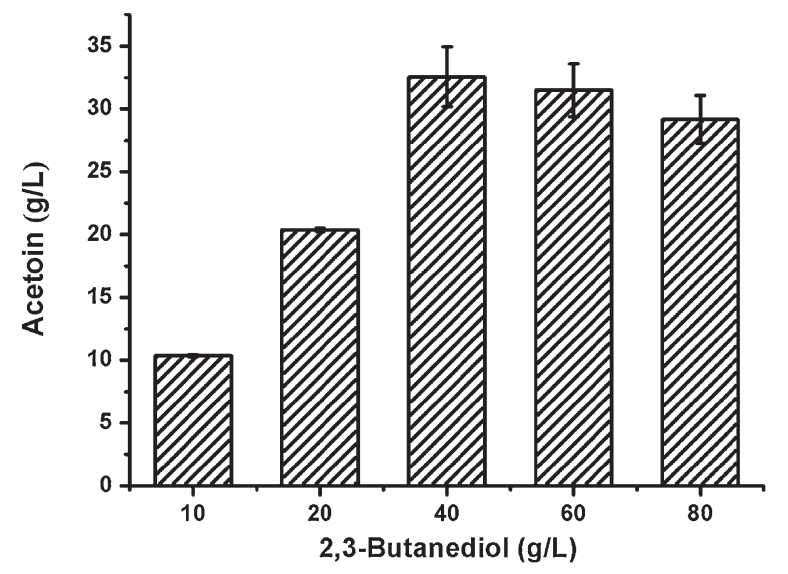

Figure 5 Effect of 2,3-butanediol concentration on acetoin production by $G$. oxydans DSM 2003. (A) Biomass; and

(B) acetoin. The experiments were conducted in $300 \mathrm{~mL}$ shake flasks containing $50 \mathrm{~mL}$ of medium at $\mathrm{pH} 6.0$ and $30^{\circ} \mathrm{C}$. The concentrations of 2,3-butanediol concentration were adjusted at $10 \mathrm{~g} / \mathrm{L}, 20 \mathrm{~g} / \mathrm{L}, 40 \mathrm{~g} / \mathrm{L}, 60 \mathrm{~g} / \mathrm{L}$, and $80 \mathrm{~g} / \mathrm{L}$.

was developed. Bioconversion was conducted at $30^{\circ} \mathrm{C}$ in $300 \mathrm{~mL}$ shake flasks containing $50 \mathrm{~mL}$ medium. The medium consisted of $20 \mathrm{~g} / \mathrm{L}$ yeast extract, $1.5 \mathrm{~g} / \mathrm{L}\left(\mathrm{NH}_{4}\right)_{2} \mathrm{SO}_{4}$, $1.5 \mathrm{~g} / \mathrm{L} \mathrm{KH}_{2} \mathrm{PO}_{4}, 0.5 \mathrm{~g} \mathrm{MgSO}_{4} 7 \mathrm{H}_{2} \mathrm{O}$, and $40 \mathrm{~g} / \mathrm{L} \mathrm{2,3-}$ butanediol. The $\mathrm{pH}$ was maintained at 6.0.

As shown in Figure 6, 37.5 g/L acetoin was obtained from $40 \mathrm{~g} / \mathrm{L}$ 2,3-butanediol after 24 hours of bioconversion. No other products were detected during the bioconversion process. The yield of acetoin was at $95.9 \%$ of the theoretical value. The ratio of $(3 R)$-acetoin and (3S)acetoin produced by strain G. oxydans DSM 2003 was analyzed by GC, which were $20.0 \%$ of $(3 R)$-acetoin and $80.0 \%$ of (3S)-acetoin, respectively (Figure 7). Since G. oxydans DSM 2003 catalyzes 2,3-butanediol oxidation with stereoselectivity, the ratio of (3R)-acetoin and (3S)acetoin would be controlled by the stereoisomer of 2,3butanediol used. 


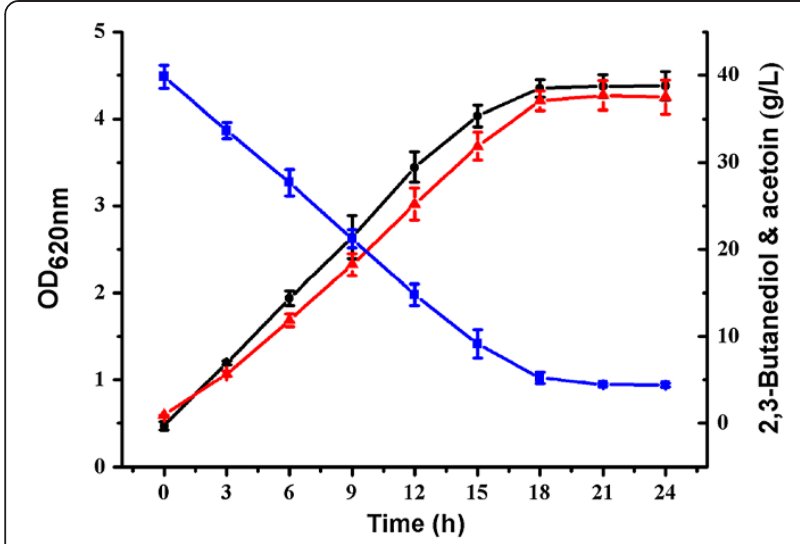

Figure 6 Time course of batch bioconversion of acetoin from 2,3-butanediol. The bioconversion was carried out at $30^{\circ} \mathrm{C}$ in $300 \mathrm{~mL}$ shake flasks containing $50 \mathrm{~mL}$ of medium at $\mathrm{pH}$ 6.0. The initial 2,3-butanediol concentration used was $40 \mathrm{~g} / \mathrm{L}$. Biomass (black circle); 2,3-butanediol (blue square); and acetoin (red triangle).

\section{Fed-batch bioconversion}

Efficient fed-batch bioconversion could enhance the concentrations of the target products. To achieve a higher product concentration, a fed-batch bioconversion was carried out with the optimized bioconversion conditions. The initial 2,3-butanediol concentration was $40 \mathrm{~g} / \mathrm{L}$, and $20 \mathrm{~g} / \mathrm{L}$ of 2,3-butanediol was added at 12, 24, and 36 hours, respectively.

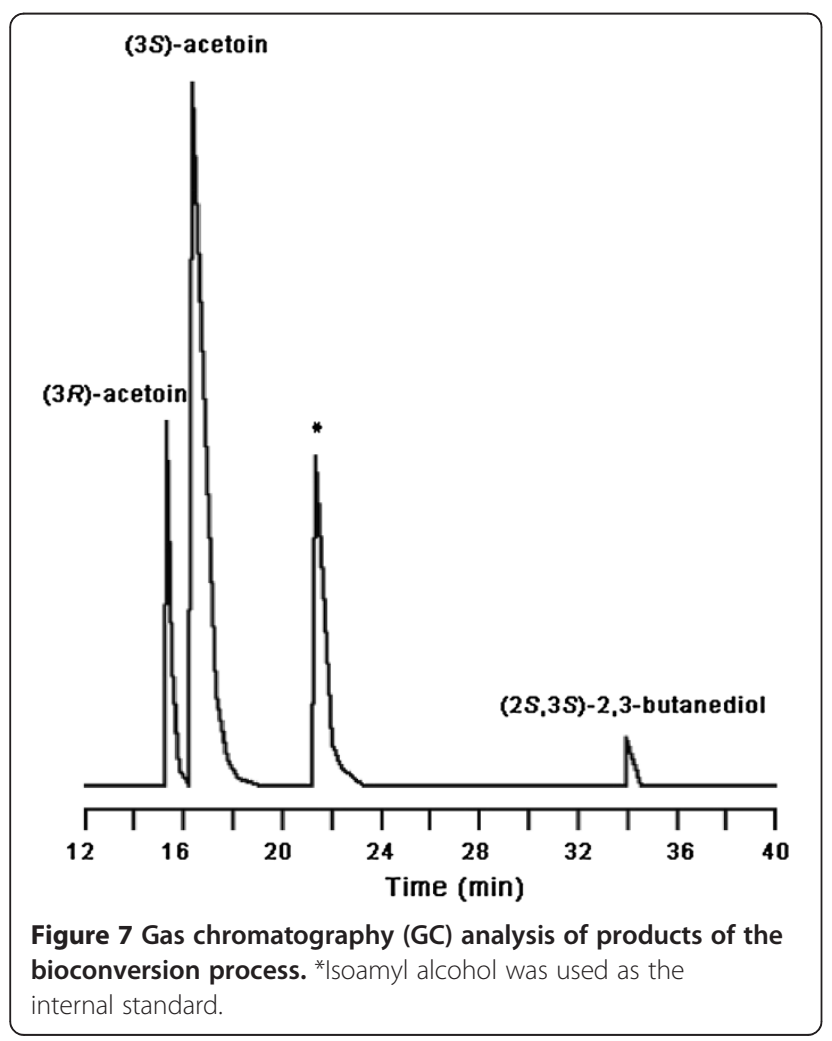

As shown in Figure 8, a high concentration of $89.2 \mathrm{~g} / \mathrm{L}$ acetoin was produced from 2,3-butanediol within 72 hours. The acetoin productivity was $1.24 \mathrm{~g} / \mathrm{L} \cdot \mathrm{h}$ with a yield of $0.91 \mathrm{~mol} / \mathrm{mol}$ 2,3-butanediol. As shown in Table 1, 89.2 $\mathrm{g} / \mathrm{L}$ of acetoin obtained in this study is the highest acetoin concentration obtained to date.

Several biotechnological routes including enzymatic or whole-cell conversion methods [20,21,40,41] and fermentative technologies $[18,19,42-47]$ have been used to produce acetoin (Table 1). Among all of the reported biotechnological processes, Sun et al. obtained the highest acetoin concentration of $75.2 \mathrm{~g} / \mathrm{L}$ with $S$. marcescens $\mathrm{H} 32$ with the expression of a water-forming NADH oxidase [16]. However, there were still considerable amounts of 2,3-butanediol generated during the acetoin fermentation process. Efforts have been tried in order to increase acetoin production through further biotransformation of the 2,3-butanediol [43]. Using 2,3-butanediol as the substrate, the recombinant $E$. coli strain that coexpressed $(2 R, 3 R)$-2,3-butanediol dehydrogenase and NADH oxidase produced acetoin at a high concentration of $36.7 \mathrm{~g} / \mathrm{L}$ [21]. On the other hand, diacetyl could also be used as the substrate for acetoin production [40,41]. Acetoin at a concentration of $13.5 \mathrm{~g} / \mathrm{L}$ was produced from diacetyl by using an $E$. coli strain that expressed stereoselective diacetyl reductase [41].

In this study, we found that G. oxydans DSM 2003 is able to produce considerable quantities of acetoin using 2,3-butanediol as the carbon source. Both concentration and yield of acetoin produced by the novel process are new records for acetoin production. Although 2,3-butanediol could be easily produced by fermentation, its large-scale microbial production requires development

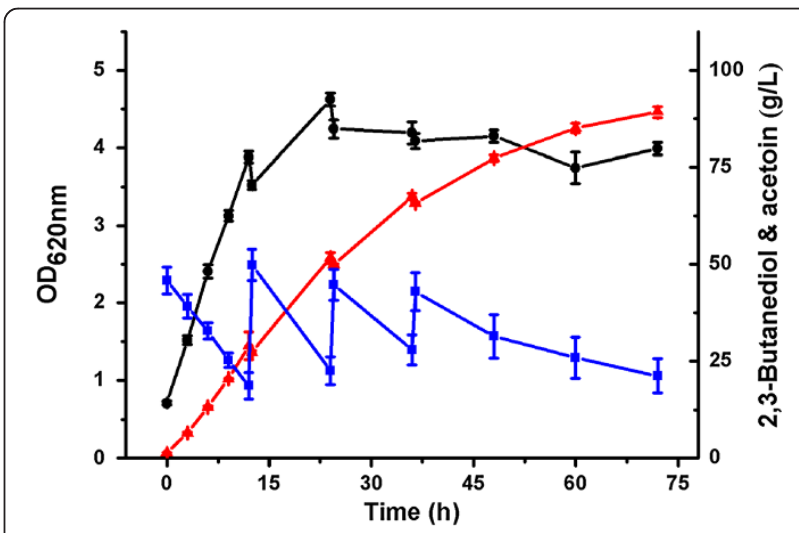

Figure 8 Time course of fed-batch bioconversion of acetoin from 2,3-butanediol. The bioconversion was carried out at $30^{\circ} \mathrm{C}$ in $300 \mathrm{~mL}$ shake flasks containing $50 \mathrm{~mL}$ of medium at $\mathrm{pH}$ 6.0. The initial 2,3-butanediol concentration used was $40 \mathrm{~g} / \mathrm{L}$, and $20 \mathrm{~g} / \mathrm{L}$ of 2,3-butanediol was added at 12, 24, and 36 hours, respectively. Biomass (black circle); 2,3-butanediol (blue square); and acetoin (red triangle). 
Table 1 Comparison of the acetoin production using different biocatalysts and fermentative strains

\begin{tabular}{|c|c|c|c|c|c|}
\hline & Substrate & $\begin{array}{c}\text { Concentration } \\
(\mathrm{g} / \mathrm{L})\end{array}$ & $\begin{array}{c}\text { Productivity } \\
(\mathrm{g} / \mathrm{L} \cdot \mathrm{h})\end{array}$ & $\begin{array}{c}\text { Yield } \\
(\mathrm{mol} / \mathrm{mol})\end{array}$ & Reference \\
\hline \multicolumn{6}{|l|}{ Biocatalyst } \\
\hline $\begin{array}{l}\text { Escherichia coli expressing glycerol } \\
\text { dehydrogenase }\end{array}$ & $\begin{array}{l}\text { Mixture of meso-2,3-butanediol } \\
\text { and }(25,3 S)-2,3 \text {-butanediol }\end{array}$ & 8.4 & 0.35 & 0.86 & {$[20]$} \\
\hline $\begin{array}{l}\text { Escherichia coli strain coexpressed }(2 R, 3 R)-2,3- \\
\text { butanediol dehydrogenase and NADH oxidase }\end{array}$ & Meso-2,3-butanediol & 36.7 & 3.06 & 0.85 & [21] \\
\hline Escherichia coli expressed diacetyl reductase & Diacetyl and glucose & 13.5 & 2.25 & 0.91 & {$[40]$} \\
\hline $\begin{array}{l}\text { Purified NADPH-dependent carbonyl reductase } \\
\text { and glucose dehydrogenase }\end{array}$ & Diacetyl and glucose & 12.2 & 9.76 & 0.85 & [41] \\
\hline \multicolumn{6}{|l|}{ Fermentative strain } \\
\hline Serratia marcescens H32 expressed NADH oxidase & Sucrose & 75.2 & 1.88 & 0.78 & [16] \\
\hline Klebsiella pneumoniae expressed NADH oxidase & Glucose & 25.9 & 0.32 & 0.16 & [18] \\
\hline Geobacillus strain XT15 & Glucose & 7.7 & 0.16 & 0.24 & [17] \\
\hline Bacillus licheniformis MEL09 & Glucose & 41.3 & 1.15 & 0.84 & {$[42]$} \\
\hline Bacillus subtilis JNA310 & Glucose & 42.2 & 0.32 & 0.57 & [43] \\
\hline $\begin{array}{l}\text { Bacillus subtilis moderately expressed the } \\
\text { transcriptional regulator AlsR }\end{array}$ & Glucose & 41.5 & 0.43 & 0.71 & [44] \\
\hline Bacillus subtilis JNA-UD-6 & Glucose & 53.9 & 0.37 & 0.74 & {$[45]$} \\
\hline Klebsiella oxytoca M1 & Glucose & 27.4 & 0.57 & 0.78 & {$[46]$} \\
\hline Bacillus subtilis CICC10025 & Glucose & 35.4 & 0.63 & 0.83 & [47] \\
\hline Gluconobacter oxydans DSM 2003 & $\begin{array}{l}\text { Mixture of meso-2,3-butanediol, (2R,3R)- } \\
\text { 2,3-butanediol, and (2S,3S)-2,3-butanediol }\end{array}$ & 89.2 & 1.24 & 0.91 & This study \\
\hline
\end{tabular}

of efficient derivative processes. Thus, the method presented in this study would not only provide a promising process for acetoin production, but would also expand the utilization of 2,3-butanediol produced from biomass.

\section{Conclusions}

An efficient process for acetoin production from 2,3butanediol was developed by using G. oxydans DSM 2003. All three stereoisomers of 2,3-butanediol could be oxidized into acetoin by the strain. Under optimal conditions, the bioconversion process exhibited rather high concentration $(89.2 \mathrm{~g} / \mathrm{L})$, productivity $(1.24 \mathrm{~g} / \mathrm{L} \cdot \mathrm{h})$, and yield (91.2\%) of acetoin. The results of this study suggest that production of acetoin using 2,3-butanediol can serve as a choice for the derivative of industrially produced 2,3-butanediol.

\section{Materials and methods Materials}

(2R,3R)-2,3-Butanediol (98.0\%), (2S,3S)-2,3-butanediol (99.0\%), and meso-2,3-butanediol (98.0\%) were purchased from Acros (Geel, Belgium). The mixture of 2,3-butanediol (76.1\% meso-2,3-butanediol, 15.9\% (2R,3R)-2,3-butanediol, and $8.0 \%(2 S, 3 S)-2,3$-butanediol) was obtained from Sinopharm (Beijing, China). Racemic acetoin, diacetyl, phenazine methosulfate (PMS), and DCPIP were purchased from Sigma. All other chemicals were of analytical grade and commercially available.

\section{Microorganism and culture conditions}

G. oxydans DSM 2003 (Deutsche Sammlung von Mikroorganismen und Zellkulturen (DSMZ), Braunschweig, Germany) was used in this study. The strain was cultured in a medium containing $20 \mathrm{~g}$ yeast extract, $1.5 \mathrm{~g}$ $\left(\mathrm{NH}_{4}\right)_{2} \mathrm{SO}_{4}, 1.5 \mathrm{~g} \mathrm{KH}_{2} \mathrm{PO}_{4}$, and $0.5 \mathrm{~g} \mathrm{MgSO}_{4} 7 \mathrm{H}_{2} \mathrm{O}$ in $1 \mathrm{~L}$ of distilled water. This medium was supplemented with 2,3-butanediol, glucose, glycerol, or sorbitol as the carbon source. The flask experiment was conducted in $300 \mathrm{~mL}$ shake flasks containing $50 \mathrm{~mL}$ fresh medium.

\section{Whole-cell DCPIP assay of the membrane-bound 2,3-butanediol dehydrogenase}

For the assay of the membrane-bound 2,3-butanediol dehydrogenase, whole cells of G. oxydans DSM 2003 were concentrated to $\mathrm{OD}_{620 \mathrm{~nm}} 4.0$ via centrifugation at $4,000 \times \mathrm{g}$ for 5 minutes. The concentrated cells were washed in $10 \mathrm{~mL} 67 \mathrm{mM}$ phosphate buffer ( $\mathrm{pH} 7.4$ ), resuspended in the same buffer and then immediately used. Activity of 2,3-butanediol dehydrogenase was determined at $30^{\circ} \mathrm{C}$ in $1 \mathrm{~mL}$ of $67 \mathrm{mM}$ phosphate buffer, $\mathrm{pH}$ 7.4, 0.2 mM PMS, 0.2 mM DCPIP, and whole cells of G. oxydans DSM 2003 (final $\mathrm{OD}_{620 \mathrm{~nm}}$ of 0.2). The 
reaction was started by addition of $25 \mathrm{mM}$ meso-2,3-butanediol, $(2 R, 3 R)$-2,3-butanediol, or (2S,3S)-2,3-butanediol [45]. The rate of DCPIP reduction was determined by measuring the absorbance changes at $600 \mathrm{~nm}$ [48]. An extinction coefficient of 21,300 for DCPIP was used for the rate calculation. One unit of oxidation activity was defined as $1 \mu \mathrm{mol}$ substrate oxidized per minute as determined by reduction of $1 \mu \mathrm{mol}$ DCPIP.

\section{Optimization of bioconversion conditions}

For the optimization of bioconversion conditions, the culture medium of $50 \mathrm{~mL}$ in $300 \mathrm{~mL}$ shake flasks were used with variation as follows: the $\mathrm{pH}$ values were 5.5 to 7.5 , temperatures were $16^{\circ} \mathrm{C}$ to $35^{\circ} \mathrm{C}$, and 2,3-butanediol concentrations were $10 \mathrm{~g} / \mathrm{L}$ to $80 \mathrm{~g} / \mathrm{L}$. Bioconversion was carried out for 12 hours and then the reaction mixture was centrifuged. The resultant supernatant was analyzed for 2,3-butanediol and acetoin by GC.

\section{Analytical methods}

Samples were withdrawn periodically and centrifuged at $12,000 \times \mathrm{g}$ for 10 minutes. The growth of $G$. oxydans DSM 2003 was determined by monitoring the absorbance at $620 \mathrm{~nm}$ using a spectrophotometer (Lengguang 721, Shanghai Precision \& Scientific Instrument Co Ltd, Shanghai, China) after an appropriate dilution. The concentrations of 2,3-butanediol and acetoin were analyzed by GC (Varian 3800, Varian, Walnut Creek, CA, USA) with the method described by Xiao et al. [21]. The GC system was equipped with a $30 \mathrm{~m}$ SPB- 5 capillary column $(0.32 \mathrm{~mm}$ inside diameter, $0.25 \mu \mathrm{m}$ film thickness; Supelco, Bellefonte, PA, USA) and a flame ionization detector. The injector and detector temperatures were both $280^{\circ} \mathrm{C}$. The column oven temperature was maintained at $40^{\circ} \mathrm{C}$ for 3 minutes, and then raised to $240^{\circ} \mathrm{C}$ at a rate of $20^{\circ} \mathrm{C} /$ minute. The injection volume was $1 \mu \mathrm{L}$. The calibration curve was used to calculate the concentration of the products. The concentration of diacetyl was measured by HPLC (Agilent 1100 series, HewlettPackard, Waldbronn, Germany) equipped with an Aminex HPX-87H column $(300 \times 7.8 \mathrm{~mm})$ (Bio-Rad, Hercules, CA, USA) and a refractive index detector [49]. The analysis was performed with a mobile phase of $10 \mathrm{mM} \mathrm{H}_{2} \mathrm{SO}_{4}$ at a flow rate of $0.4 \mathrm{~mL} /$ minute and at $55^{\circ} \mathrm{C}$.

\section{Additional files}

Additional file 1: Figure S1. Time course of G. oxydans DSM 2003 growth in the medium containing (A) $20 \mathrm{~g} / \mathrm{L}$ yeast extract or (B) $10 \mathrm{~g} / \mathrm{L}$ glycerol.

Additional file 2: Figure S2. Analysis of the utilization of acetoin by G. oxydans DSM 2003.

Additional file 3: Table S1. Effects of carbon sources on the activities of 2,3-butanediol dehydrogenases.

\section{Abbreviations}

DCPIP: 2,6-dichlorophenolindophenol; DSMZ: Deutsche Sammlung von Mikroorganismen und Zellkulturen; GC: Gas chromatography; HPLC: Highperformance liquid chromatography; PMS: Phenazine methosulfate.

\section{Competing interests}

The authors declare that they have no competing interests.

\section{Authors' contributions}

CG and CM participated in the design of the study. XW and ML executed the experimental study. $\mathrm{KL}$ and $\mathrm{LZ}$ analyzed the data. CG, CM, and PX contributed reagents and materials. CG, CM, and PX wrote and revised the manuscript. All authors read and approved the final manuscript.

\section{Acknowledgements}

This study was supported by the Chinese National Program for High Technology Research and Development (2011AA02A207, 2012AA022104) and the Program for High Technology Research and Development of Shandong province (2012GSF12119).

\section{Author details}

'State Key Laboratory of Microbial Technology, Shandong University, Jinan 250100, People's Republic of China. ${ }^{2}$ State Key Laboratory of Microbial Metabolism, School of Life Sciences and Biotechnology, Shanghai Jiao Tong University, Shanghai 200240, People's Republic of China.

Received: 20 July 2013 Accepted: 22 October 2013

Published: 31 October 2013

\section{References}

1. Celińska E, Grajek W: Biotechnological production of 2,3-butanediolcurrent state and prospects. Biotechnol Adv 2009, 27:715-725.

2. Ji XJ, Huang H, Ouyang PK: Microbial 2,3-butanediol production: a stateof-the-art review. Biotechnol Adv 2011, 29:351-364.

3. Zeng AP, Sabra W: Microbial production of diols as platform chemicals: recent progresses. Curr Opin Biotechnol 2011, 22:749-757.

4. Ji XJ, Huang H, Du J, Zhu JG, Ren LJ, Hu N, Li S: Enhanced 2,3-butanediol production by Klebsiella oxytoca using a two-stage agitation speed control strategy. Bioresour Technol 2009, 100:3410-3414.

5. Ma C, Wang A, Qin J, Li L, Ai X, Jiang T, Tang H, Xu P: Enhanced 2,3butanediol production by Klebsiella pneumoniae SDM. Appl Microbiol Biotechnol 2009, 82:49-57.

6. Jurchescu IM, Hamann J, Zhou X, Ortmann T, Kuenz A, Prüße U, Lang S: Enhanced 2,3-butanediol production in fed-batch cultures of free and immobilized Bacillus licheniformis DSM 8785. App/ Microbiol Biotechnol 2013, 97:6715-6723.

7. Häßler T, Schieder D, Pfaller R, Faulstich M, Sieber V: Enhanced fed-batch fermentation of 2,3-butanediol by Paenibacillus polymyxa DSM 365 . Bioresour Technol 2012, 124:237-244

8. $\mathrm{Ng} C Y$, Jung MY, Lee J, Oh MK: Production of 2,3-butanediol in Saccharomyces cerevisiae by in silico aided metabolic engineering. Microb Cell Fact 2012, 11:68.

9. Wang A, Xu Y, Ma C, Gao C, Li L, Wang Y, Tao F, Xu P: Efficient 2,3butanediol production from cassava powder by a crop-biomass-utilizer, Enterobacter cloacae subsp. dissolvens SDM. PLoS One 2012, 7:e40442.

10. Rao B, Zhang LY, Sun J, Su G, Wei D, Chu J, Zhu J, Shen Y: Characterization and regulation of the 2,3-butanediol pathway in Serratia marcescens. Appl Microbiol Biotechnol 2012, 93:2147-2159.

11. Zhang L, Sun J, Hao Y, Zhu J, Chu J, Wei D, Shen Y: Microbial production of 2,3-butanediol by a surfactant (serrawettin)-deficient mutant of Serratia marcescens H30. J Ind Microbiol Biotechnol 2010, 37:857-862.

12. Yang TW, Rao ZM, Zhang X, XU MJ, Xu ZH, Yang ST: Fermentation of biodiesel-derived glycerol by Bacillus amyloliquefaciens: effects of co-substrates on 2,3-butanediol production. Appl Microbiol Biotechnol 2013, 97:7651-7658.

13. Kopke M, Mihalcea C, Liew F, Tizard JH, Ali MS, Conolly JJ, Al-Sinawi B, Simpson SD: 2,3-Butanediol production by acetogenic bacteria, an alternative route to chemical synthesis, using industrial waste gas. Appl Environ Microbiol 2011, 77:5467-5475. 
14. Barrett EL, Collins EB, Hall BJ, Matoi SH: Production of 2,3-butylene glycol from whey by Klebsiella pneumoniae and Enterobacter aerogenes. J Dairy Sci 1983, 66:2507-2514.

15. Oliver JW, Machado IM, Yoneda H, Atsumi S: Cyanobacterial conversion of carbon dioxide to 2,3-butanediol. Proc Natl Acad Sci U S A 2013, 110:1249-1254.

16. Sun JA, Zhang LY, Rao B, Shen $Y L$, Wei DZ: Enhanced acetoin production by Serratia marcescens $\mathrm{H} 32$ with expression of a water-forming NADH oxidase. Bioresour Technol 2012, 119:94-98.

17. Liu Z, Qin J, Gao C, Hua D, Ma C, Li L, Wang Y, Xu P: Production of (2S,3S)2,3-butanediol and (3S)-acetoin from glucose using resting cells of Klebsiella pneumonia and Bacillus subtilis. Bioresour Technol 2011, 102:10741-10744.

18. Ji XJ, Xia ZF, Fu NH, Nie ZK, Shen MQ, Tian QQ, Huang H: Cofactor engineering through heterologous expression of an NADH oxidase and its impact on metabolic flux redistribution in Klebsiella pneumoniae. Biotechnol Biofuels 2013, 6:7

19. Xiao Z, Wang X, Huang Y, Huo F, Zhu X, Xi L, Lu JR: Thermophilic fermentation of acetoin and 2,3-butanediol by a novel Geobacillus strain. Biotechnol Biofuels 2012, 5:88

20. Yamada-Onodera K, Yamamoto H, Kawahara N, Tani Y: Expression of the gene of glycerol dehydrogenase from Hansenula polymorpha D1-1 in Escherichia coli for the production of chiral compounds. Acta Biotechnol 2002, 22:355-362.

21. Xiao Z, Lv C, Gao C, Qin J, Ma C, Liu Z, Liu P, Li L, Xu P: A novel whole-cell biocatalyst with $\mathrm{NAD}^{+}$regeneration for production of chiral chemicals. PLoS One 2010, 5:e8860.

22. Thanh $\mathrm{TN}$, Jürgen $B$, Bauch $M$, Liebeke $M$, Lalk $M$, Ehrenreich $A$, Evers $S$ Maurer $\mathrm{KH}$, Antelmann $\mathrm{H}$, Ernst F, Homuth $\mathrm{G}$, Hecker M, Schweder T: Regulation of acetoin and 2,3-butanediol utilization in Bacillus licheniformis. Appl Microbiol Biotechnol 2010, 87:2227-2235.

23. Hsu JL, Peng HL, Chang HY: The ATP-binding motif in AcoK is required for regulation of acetoin catabolism in Klebsiella pneumoniae CG43. Biochem Biophys Res Commun 2008, 376:121-127.

24. Xiao Z, Xu P: Acetoin metabolism in bacteria. Crit Rev Microbiol 2007 33:127-140.

25. Yamamoto $H$, Uchiyama S, Sekiguchi J: Cloning and sequencing of a $40.6 \mathrm{~kb}$ segment in the 73 degrees-76 degrees region of the Bacillus subtilis chromosome containing genes for trehalose metabolism and acetoin utilization. Microbiology 1996, 142:3057-3065.

26. Gao K, Wei D: Asymmetric oxidation by Gluconobacter oxydans. Appl Microbiol Biotechnol 2006, 70:135-139.

27. Gupta A, Singh VK, Qazi GN, Kumar A: Gluconobacter oxydans: its biotechnological applications. J Mol Microbiol Biotechnol 2001, 3:445-456.

28. Wei G, Yang X, Gan T, Zhou W, Lin J, Wei D: High cell density fermentation of Gluconobacter oxydans DSM 2003 for glycolic acid production. $J$ Ind Microbiol Biotechnol 2009, 36:1029-1034.

29. Peters B, Mientus M, Kostner D, Junker A, Liebl W, Ehrenreich A: Characterization of membrane-bound dehydrogenases from Gluconobacter oxydans $621 \mathrm{H}$ via whole-cell activity assays using multideletion strains. Appl Microbiol Biotechnol 2013, 97:6397-6412.

30. Hoshino T, Sugisawa T, Shinjoh M, Tomiyama N, Miyazaki T: Membranebound D-sorbitol dehydrogenase of Gluconobacter suboxydans IFO 3255-enzymatic and genetic characterization. Biochim Biophys Acta 2003, 1647:278-288

31. Voss J, Ehrenreich A, Liebl W: Characterization and inactivation of the membrane-bound polyol dehydrogenase in Gluconobacter oxydan DSM7145 reveals a role in meso-erythritol oxidation. Microbiology 2010, 156:1890-1899.

32. Ge X, Zhao Y, Hou W, Zhang W, Chen W, Wang J, Zhao N, Lin J, Wang W, Chen $M$, Wang $Q$, Jiao $Y$, Yuan $Z$, Xiong $X$ : Complete genome sequence of the industrial strain Gluconobacter oxydans H24. Genome Announc 2013, 1:e00003-e00013.

33. Prust $C$, Hoffmeister $M$, Liesegang $H$, Wiezer A, Fricke WF, Ehrenreich $A$, Gottschalk G, Deppenmeier U: Complete genome sequence of the acetic acid bacterium Gluconobacter oxydans. Nat Biotechnol 2005, 23:195-200.

34. Gao L, Zhou J, Liu J, Du G, Chen J: Draft genome sequence of Gluconobacter oxydans WSH-003, a strain that is extremely tolerant of Saccharides and Alditols. J Bacteriol 2012, 194:4455-4456.
35. Wang Q, Chen T, Zhao X, Chamu J: Metabolic engineering of thermophilic Bacillus licheniformis for chiral pure D-2,3-butanediol production. Biotechnol Bioeng 2012, 109:1610-1621.

36. Yu B, Sun J, Bommareddy RR, Song L, Zeng AP: Novel (2R,3R)-2,3butanediol dehydrogenase from potential industrial strain Paenibacillus polymyxa ATCC 12321. Appl Environ Microbiol 2011, 77:4230-4233.

37. González E, Fernández MR, Larroy C, Solà L, Pericàs MA, Parés X, Biosca JA: Characterization of a (2R,3R)-2,3-butanediol dehydrogenase as the Saccharomyces Cerevisiae YAL060W gene product. Disruption and induction of the gene. J Biol Chem 2000, 275:35876-35885.

38. Nicholson WL: The Bacillus subtilis ydjL (bdhA) gene encodes acetoinreductase/2,3-butanediol dehydrogenase. Appl Environ Microbiol $2008,74: 6832-6838$

39. Zhang L, Xu Q, Zhan S, Li Y, Lin H, Sun S, Sha L, Hu K, Guan X, Shen Y: A new $\mathrm{NAD}(\mathrm{H})$-dependent meso-2,3-butanediol dehydrogenase from an industrially potential strain Serratia marcescens H30. Appl Microbiol Biotechnol 2013. doi:10.1007/s00253-013-4959-x.

40. Gao J, Xu YY, Li FW, Ding G: Production of S-acetoin from diacetyl by Escherichia coli transformant cells that express the diacetyl reductase gene of Paenibacillus polymyxa ZJ-9. Lett Appl Microbiol 2013, 57:274-281.

41. Gao C, Zhang L, Xie Y, Hu C, Zhang Y, Li L, Wang Y, Ma C, Xu P: Production of (3S)-acetoin from diacetyl by using stereoselective NADPH-dependent carbonyl reductase and glucose dehydrogenase. Bioresour Technol 2013, 137:111-115.

42. Liu YF, Zhang SL, Yong YC, Ji ZX, Ma X, Xu ZH, Chen SW: Efficient production of acetoin by the newly isolated Bacillus licheniformis strain MEL09. Process Biochem 2011, 46:390-394

43. Zhang X, Yang TW, Lin Q, Xu MJ, Xia HF, Xu ZH, Li HZ, Rao ZM: Isolation and identification of an acetoin high production bacterium that can reverse transform 2,3-butanediol to acetoin at the decline phase of fermentation. World J Microbiol Biotechnol 2011, 27:2785-2790.

44. Zhang X, Zhang R, Bao T, Yang T, Xu M, Li H, Xu Z, Rao Z: Moderate expression of the transcriptional regulator ALsR enhances acetoin production by Bacillus subtilis. J Ind Microbiol Biotechnol 2013, 40:1067-1076

45. Zhang X, Zhang R, Yang T, Zhang J, Xu M, Li H, Xu Z, Rao Z: Mutation breeding of acetoin high producing Bacillus subtilis blocked in 2,3-butanediol dehydrogenase. World J Microbiol Biotechnol 2013 29:1783-1789.

46. Cho S, Kim KD, Ahn JH, Lee J, Kim SW, Um Y: Selective production of 2,3-butanediol and acetoin by a newly isolated bacterium Klebsiella oxytoca M1. Appl Biochem Biotechnol 2013, 170:1922-1933.

47. Xiao ZJ, Liu PH, Qin JY, Xu P: Statistical optimization of medium components for enhanced acetoin production from molasses and soybean meal hydrolysate. Appl Microbiol Biotechnol 2007, 74:61-68.

48. Ma CQ, Gao C, Qiu JH, Hao JR, Liu WW, Wang AL, Zhang YN, Wang M, Xu P: Membrane-bound L- and D-lactate dehydrogenase activities of a newly isolated Pseudomonas stutzeri strain. Appl Microbiol Biotechnol 2007 77:91-98.

49. Gao C, Zhang W, Lv CJ, Li LX, Ma CQ, Hu CH, Xu P: Efficient production of 2-oxobutyrate from 2-hydroxybutyrate using whole cells of Pseudomonas stutzeri strain SDM. Appl Environ Microbiol 2010, 76:1679-1682.

doi:10.1186/1754-6834-6-155

Cite this article as: Wang et al:: Efficient bioconversion of 2,3-butanediol into acetoin using Gluconobacter oxydans DSM 2003. Biotechnology for Biofuels 2013 6:155 